\title{
El derecho real de superficie forestal en el ordenamiento juridico positivo Argentino
}

\author{
Luis O. Andorno
}

"En memoria del ilustrísimo catedrático y jurista brasileño Profesor Clóvis do Couto e Silva, gran amigo de la Argentina, cuya vida llena de virtudes, de bondad, de desinterés y de sapiencia debe orientar a las generaciones futuras de las distintas partes del mundo, en estos tiempos difíciles por los que atraviesa la Humanidad."

Sumario: I. Introducción. II. Caracterización del derecho real de superficie forestal. III. Derecho real autónomo de superficie forestal temporario. Derecho de enajenar el inmueble afectado a superficie forestal. IV.Nacimiento del derecho real de superficie forestal. Publicidad registral.V.Duración del derecho real de superficie forestal. VI. Destrucción total o parcial de lo plantado. Derecho de reforestación. VII. Extinción del derecho real de superficie forestal. VIII. Obligaciones que pesan sobre el superficiario forestal. IX. El supuesto especial de la extinción del derecho real de superficie forestal por consolidación. X. Efectos de la extinción del derecho de superficie forestal. XI. Modificación del artículo 2614 del Código Civil.

\section{Introducción.}

Con verdadero júbilo intelectual recibimos la noticia relativa a la incorporación a nuestro ordenamiento jurídico positivo del derecho real de superficie forestal a través de la ley No. 25.509 promulgada de hecho con fecha 11 de diciembre de 2001. Desde hace casi dos décadas venimos bregando incesamente por la regulación específica del derecho de superficie en nuestro país, con suficiente sustento doctrinatio y de legislación comparada,conforme surge de los diversos trabajos doctrinarios de nuestra autoría, publicados sobre el particular y que se reflejarán en este artículo que ofrecemos a la consideración de los amables lectores. Así procuraremos poner de relieve los aspectos más salientes del novel instituto disciplinado por dicha ley. 
Al respecto, debe decirse inicialmente que se caracteriza al derecho de superficie, como a la posibilidad de que una persona pueda ser propietaria de una construcción o de una plantación ubicada en terreno ajeno, según la adecuada caracterización del jurista portugués José Oliveira Ascensao, en relación al derecho vigente en su patria, cuando dice que la superficie "es el derecho real de tener una cosa propia incorporada en terreno ajeno" (José Oliveira Ascensao, Direitos reais, Lisboa, 1978, p. 507).

El propio codificador en su nota al artículo 2503 del Código Civil-que suprimió de modo expreso el derecho de superficie, junto a otros derechos reales en el art. 2614, C.C.,recuerda que en Roma "el derecho del superficiario consistía en poder hacer obras, como edificar casas, plantar árboles, etc., adherentes al suelo, sobre las cuales tenía un derecho de propiedad, independiente del de propietario del terreno, el cual, sin embargo, podía por derecho propio, hacer sótanos y otros trabajos subterráneos bajo de la misma superficie que pertenecía a otro, con tal que no perjudicase los derechos del superficiario, así como el superficiario no podía deteriorar el fondo del terreno".

En el nuevo Código Civil del Brasil, ley 10.406/2002, que entrará a regir el 11 de enero de 2003, uno de cuyos antecedentes es el Proyecto brasileño de Código Civil de 1975, en el que colaborara nuestro ilustre homenajeado y querido amigo, el Profesor Clóvis do Couto e Silva, se dice que "el propietario puede conceder a otro el derecho de construir o de plantar en su terreno, por tiempo determinado, mediante escritura pública debidamente inscripta en el Registro de Inmuebles" (Art. 1368). Como se advierte se admite no solamente la posibilidad de construir en terreno ajeno, sino también la de plantar en el mismo (v. nuestro trabajo "Los deechos reales en el nuevo Código Civil del Brasil, con particular referencia al derecho se superficie", entregas de Zeus de los días 15 y 16 de abril de 2002).

Para una reseña histórica acerca del derecho de superficie remitimos a nuestro trabajo:"El derecho de superficie" (J.A. 1985-IIL-653).

En síntesis y con palabras simples, a la luz de lo que llevamos expuesto, nos parece que podemos caracterizar al derecho de superficie como al derecho real de tener una cosa propia en terreno ajeno.

Ahora bien, la ley 25.509, en cuanto complementaria del Código Civil (art. 14 de dicha ley) incorpora a nuestra legislación civil una variante del derecho real de superficie, esto es, el derecho teal de superficie forestal.

El mismo reconoce como antecente inmediato la ley No. 25080, llamada "Ley de inversiones para bosques cultivados", generada en un proyecto del P.E., sancionada el 16 de diciembre de 1998, que propicia un régimen de promoción de las inversiones que se efectúen en nuevos emprendimientos forestales y en las ampliaciones de los bosques existentes.

Podría decirse así que el mencionado derecho real de superficie forestal constituye en rigor de verdad un verdadero complemento de dicha ley de inversicnes forestales No. 25.080 .

Por tal razón nos ha parecido de interés recordar en el presente comentario lo manifestado por distintos diputados nacionales en la 10 ${ }^{a}$. sesión ordinaria (especial) realizada 


\section{El derecho real de superficie forestal en el ordenamiento juridico positivo Argentino 163}

en la Cámara de Diputados de la Nación durante los días 9 y 10 de setiembre de 1998, en ocasion del tratamiento parlamentario de dicho ley.

Así, el diputado nacional por la provincia de Misiones, Barrios Arrechea recordó que mientras la Argentina tiene una superficie forestal plantada que oscila entre $700 \mathrm{y}$ 800 mil héctareas, los hermanos chilenos tienen 1.800 .000 hectáreas.

Recuerdó luego dicho legislador que mientras la Argentina viene plantando entre 20 y 25 mil hectáreas de bosques por año, Brasil 360 mil hectáreas por año, los EE.UU 1.800 .000 hectáreas y Rusia y China-que son los países que más forestan en el mundo4.500.000 hectáreas por año. Agregó asimismo que nosotros aspiramos a una meta de 2.000.000 de héctáreas en los próximos diez años. La puesta en práctica de dicho ley de inversiones para bosques cultivados, y su complemento, la incorporación del derecho real de superficie forestal implicaría la creación de unos 60 mil empleos de carácter permanente en forma directa a los que accederán las economías regionales y la población de baja capacitación.

Además, otro beneficio directivo contemplado en la normativa se vincula con la industrialización de la materia prima, pues la Argentina es deficitaria en este sentido. Tenemos un déficit de entre 600 y 800 millones de dólares por año. Exportamos más volúmenes que los que importamos. Por cada tonelada de madera que exportamos recibimos 460 dólares y por cada tonelada que importamos pagamos 1.200 dólares.Esto significa por tanto que estamos comprando mano de obra extranjera porque no industrializamos la materia prima que producimos. Por lo demás, agrega dicho legislador, que la industrilización contempla no solamente la tabla, sino también el tablero, el mueble, la vivienda, y en fin, todo lo que se puede hacer con la madera.

Se indica asimismo que Suecia es un país forestal por excelencia y que los argentinos a través de la mencionada legislación forestal esperamos seguir ese camino.

Tocante al derecho real de superficie forestal se puso de relieve que el mismo constituiye un derecho real, por el cual terceras personas van a poder implantar dicha propiedad. Eso significará que mucha gente que está en la industria y que no posee capacidad para comparar tierras, no va a necesitar hacerlo. Con un convenio en el área privado realizada con un propietario de tierras ociosas, van a poder implantar bosques en el terreno ajeno, y todos serán beneficiarios de la nueva legislación en materia forestal. Esto se concretará a través de cuantiosas inversiones que se podrán hacer con fondos prevenientes tanto del país cuanto con capitales que vengan del extranjero.

En dicho debate parlamentario en torno a la mencionada ley 25.080 se señaló asimismo con acierto por parte de la diputada Muller que la aprobación del referido marco legal en materia forestal contribuirá también al cumplimiento de los compromisos asumidos por nuestro pais en la segunda Conferencia de las Naciones Unidas sobre medio ambiente denominada Cumbre de la Tierra, realizada en 1992 en Rio de Janeiro, a la que asistieron más de ciento cincuenta presidentes de distintos países. De esta manera no solamente se tiende a la promoción de una actividad económica singular sino que también se crea la posiblidad de mejorar las condiciones ambientales de las regiones en las que este régimen 
se pueda desarrollar:En efecto, el incremento de las masas boscosas y de todas las superficies forestales-agregó dicha legisladora- es altamente beneficioso, ya que se trata de elementos de la naturaleza que generan un efecto de sumidero, entendiéndose por tal a cualquier proceso, actividad o mecanismo que absorbe gas de efecto invernadero.

Formuladas estas consideraciones previas, pasamos ahora a ocupanos específicamente acerca del referido derecho real de superficie forestal introducido a nuestro régimen jurídica por la mencionada ley 25.509.

\section{Caracterización del derecho real de superficie forestal.}

A fin de orientarnos sobre el particular, corresponde recordar en primer lugar que el artículo $1^{2}$. de dicha ley 25.509 dice: "Créase el derecho real de superficic forestal, constituido a favor de terceros, por los titulares de dominio o condominio sobre un inmueble susceptible de forestación o silvicultura, de conformidad al régimen previsto en la ley de Inversiones para Bosques Cultivados, y a lo establecido en la presente ley". Debe decirse además que como consecuencia de ello, se agrega asimismo como inciso octavo del artículo 2603 del Código Civil a tal "Superficie forestal" (art. 13, ley 25.509).

Como fácilmente se desprende del texto de este articulo, y acaba de señalarse, se incopora a nuestro ordenamiento civil el derecho real de superficie forestal, cuya caracterización encuadra en el concepto que hemos dado en el punto anterior, esto es, la posibilidad de que un tercero pueda forestar en terreno ajeno.

Por lo demás, dicho articulo que acaba de transcribirse, en cuanto se establece que tal derecho real de superficie forestal puede ser constituido "por los titulares de dominio o condominio", coincide con lo propiciado en el artículo 2019 (ahora artículo 1982, luego del dictamen de la Comisión de Legislación General de la Cámara de Diputados de la Nación, del 1‥ de noviembre de 2001) del Proyecto de Código Civil de 1998,-otra fuente inmediata de la ley-actualmente a consideración de nuestro Congreso Nacional en cuanto dice que pueden constituir el derecho real de superficie "los titulies de derechos reales de dominio, condominio y propiedad horizontal". Remitimos al respecto a nuestro trabajo "El derecho de superficie en el Proyecto de Código Civil de 1998", aparecido en J.A. 2000-II-890.)

La omisión de la mención a la propiedad horizontal consignada expresamente en dicho Proyecto de 1998 aparece como natural, habida cuenta del objeto sobre el cual recae el nuevo derecho disciplinado por la mencionada ley 25.509 .

Parece obvio destacar que en el caso de constitución de derecho real de superficie forestal por los condóminos, como lo prevé de modo expreso el artículo transcripto, será menester el consentimiento de todos los condóminos, a tenor de lo disciplinado por los artículos 2680, 2682, 2684, 2676 y conexos del Código Civil, desde que el derecho de superficie no podría ser ejercido sobre una parte indivisa del inmueble (cf. nuestro comentario a dichos artículos en nuestro "Código Civil Anotado-Libro III-Derechos Reales", Tomo 2, Editorial Zavalia, Bs. As., 1974, ps. 437, 447, 453, 457 y ss., en colaboración con Roque Garrido). 
En la parte final de dicho art. 1 . de esta ley 25.509 dispone que el derecho real de superficie forestal recaerá como se ha visto "sobre un inmueble susceptible de forestación o silvicultura, de conformidad al régimen previsto en la Ley de Investiones para Bosques Cultivados, y a lo establecido en la presente ley".

Ello significa por tanto que resulta fundamental remitirnos en primer lugar a la mencionada Ley de Inversiones para Bosques Cultivados No. 25.080, promulgada el 15 de enero de 1999 y publicada en el Boletin Oficial del 19 de enero de dicho año.

Y así tenemos que en el referido debate parlamentario de la misma, en la Cámara de Diputados de la Nación de los días 9 y 10 de setiembre de 1998, se recordó que conforme a dicho régimen legal, "además de los pinos y de los eucaliptos, podremos volver a ver otros árboles que tanto amamos los argentinos, entre ellos los cedros, los lapachos, los algarrobos, los quebrachos y todo ese paisaje que estamos esperando. Ello será posible en la medida en que decidamos sancionar esta iniciativa, pues va a signficar muchos años de bonanza para las economías regionales que hoy tanto necesitan esta inyección de optimismo, dinero y trabajo" (diputado Barrios Arrechea). En tal ocasión, dijo asimismo dicho legislador que "el mercado intemacional continúa demandando madera de plantaciones. Las condiciones naturales de la Argentina son excepcionalmene adecuadas para la producción de especies madereras de rápido crecimicnto, con ritmos de desarrollo difíciles de superar en cualquier otro lugar del mundo...".

En forma coincidente, la cliputada Méndez de Medina Lareu, sostuvo que "el objetivo de este proyecto de ley, como ya se dijo, fundamentalmente es el de incrementar la superficie forestada en más de dos millones de hectáreas, es decir, triplicar en un plazo de diez años el área cultivada actualmente, consolidando así el desarrollo del sector foresto industrial argentino de manera tal que cree una base de recursos leñosos de alta calidad y competitividad con destino a una industria transformadora, moderna y relevante". En el mismo sentido, en dicho debate en la Cámra de Diputados, sostuvo el diputado Martínez Zuccardi que la ley en tratamiento procura "promover el desarrollo forestal argentino dentro de un marco en el cual la madera se ha convertido en un recurso escaso en el mundo a partir de la práctica depredadora del hombre y de su disminución por el abuso en la explotación de los bosques preexistentes. Pero al mismo tiempo esto la convierte en una actividad que tiene un futuro y un horizonte económico promisorio y alentador".

En forma coincidente se tiene que los doctores Alicia Goldenberg y Manuel C. Gómez de la Lastra en su interesante trabajo titulado "Los fondos fiduciarios de inversión directa y el derecho real de superficie,, pilares para el desarrollo forestal argentino "( J.A. 1998 III-763), comentando el proyecto que sirvió de antecedente a las posteriores leyes 25.080 y 25.509, señalan que la inversión forestal constituye "un verdadero "potencial de crecimiento", toda vez que, actualmente, se observa a esta actividad como una fuente receptora de distintas opciones de inversión, dado que se le reconocen características que la hacen apropiada para satisfacer una amplia gama de posibilidades". Dicen asimismo que en cuanto al nuevo derecho real de superficie, que en definitiva resultó incorporado al ordenamiento jurídico argentino que el mismo "apunta a lograr una óptima utilización 
de los inmuebles destinados a la actividad forestal y, en especial, facilitar las operaciones de financiamientos que emprendimientos de esta naturaleza requieren, sobre todo teniendo en cuenta los enormes lapsos que los mismos necesitan para fructificar". Y que "dicho derecho real no configura un cambio en el derecho de propiedad, sino que establece la posibilidad de que el propietario de un inmueble pueda constituirlo contractual y libremente, a favor del mismo y de un tercero, es decir "en mutuo beneficio", sobre las plantaciones por aquél o por éste realizadas en dicho inmueble "(J.A. 1998-HI-767).

Por lo demás, en el artículo 4․ de la referida Ley de Inversiones para bosques cultivados No. 25.080 se puntualiza que "Entiéndose por bosque implantado o cultivado, a los efectos de esta ley, el obtenido mediante siembra o plantación de especies maderables nativas y lo exóticas adaptadas ecológicamente al sitio, con fines especialmente comerciales o industriales, en tierras que, por sus condiciones naturales, ubicación y aptitud sean susceptibles de forestación o reforestación y que al momento de la sanción de la presente ley no estén cubiertas por masas arbóreas nativas o bosques permanentes o protectores, estos últimos definidos previamente como tales por las autoridades provinciales, salvo la existencia de un plan de manejo sustentable para bosques degradados a fin de enriquecerlos, aprobado por la provincia respectiva".

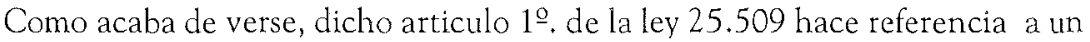
inmueble susceptible de forestación "o silvicultura". A propósito de esta última expresión, el Diccionario de la Real Academia Española señala que silvicultura (del latin silva, selva y cultura, cultura), significa en su primera acepción : "cultura de los bcsquess o montes" (Real Academia Española. Diccionario de la Lengua Española, Madrid, 1952, ps.1880/ 1881), de lo que se desprende que tal acepción coincide con la caracterización legal del bosque efectuada por el mencionado artículo $4^{\circ}$. de dicha ley 25.080 .

En conclusión, como se desprende del debate parlamentario en torno a esta ley tanto la ley 25.080 cuanto la ley 25.509 que complementa a aquélla, procuran crear una base de recursos leñosos de alta calidad y competitividad con destino a una industria transformadora, modema y relevante. A simple título ejemplificativo se ha hecho mención a los pinos, eucaliptos, cedros, lapachos, algarrobos, quebrachos y especies similares.

Debe decirse asimismo que la posibilidad de que el derecho de superficie comprendiera no solamente la facultad de construir sino también la de forestar en terreno ajeno, fue prevista también en el mencionado art. 1982 del Proyecto de Código Civil de 1998, siendo esto último - el derecho a forestar en terreno ajeno-una verdadera innovación en relación a los proyectos anteriores (Proyectos de 1987 y de 1993), que también sirvió de antecedentes inmediato a la presente ley 25.509, que estamos comentando.

Añádase que en fecha reciente, esto es, el 31 de diciembre de 2001, se promulgó en la Comunidad Autónoma de Cataluña,(España), la ley 22/2001, que regula "Los derechos de Superficie, de Servidumbre y de Adquisición Voluntaria o Preferente", que caracteriza al Derecho Real de Superficie como al "Derecho real limitado sobre una finca ajena que atribuye temporalmente la propiedad de las construcciones o plantaciones que estén includas en la misma. En virtud del derecho de superficie se mantiene la separación entre la propiedad de lo que se construye o se planta y la del suelo en el que se efectúa la construccióno plantación". 
Como se desprende del texto transcripto tal derecho de superficie incorporado a la legilsación de la Comunidad Autónoma de Cataluña en fecha reciente, respondiendo a modernas tendencias en la materia, prevé no solamente la posibilidad de construir en terreno ajeno, sino también la de plantar, en el mismo.

III. Derecho real autonómo de superficie forestal temporario. Derecho de enajenar el inmueble afectado a superficie forestal.

1.El articulo 2\%. de la ley 25.509 dice: "El derecho real de superficie forestal es un derecho real autónomo sobre cosa propia temporario, que otorga el uso, goce y disposición jurídica de la superficie de un inmueble ajeno con la facultad de realizar forestacion o silvicutura y hacer propio lo plantado o adquirir la propiedad de plantaciones ya existentes gravadas con derecho real de garantia"..

De la simple lectura de este texto legal se desprende que el mismo ha previsto dos vías para acceder a la propiedad superficiaria. La primera de ellas, presupone la existencia de un inmueble baldío sobre el cual el propietario o copropietarios del terreno otorgarán la facultad de realizar forestación o silvicultura.

La segunda vía admite la posibilidad de adquirir la propiedad de plantaciones ya existentes.

En ambos supuestos el derecho real de propiedad forestal constituido a través de los dos procedimientos previstos por la ley es posible gravarlo con derecho real de garantía.

Nos ocuparemos en primer lugara acerca del primer camino. Se trata como se ha visto de la posibilidad de realizar una forestación sobre un inmueble baldío ajeno. Consideraremos lluego el segundo camino.

Como lo hemos señalado en nuestro referido trabajo (J.A. 2000-II-890), aquíse experimenta una verdadera metamorfosis, toda vez que el derecho de forestar nace sobre cosa ajena y se convierte en derecho real sobre cosa propia una vez concretada la plantación.

Se regula así el llamado "Derecho de plantar", siguiendo los lineamientos del Código Civil italiano de 1942, (arts. 952, 955 y concordantes), aun cuando este cuerpo legal se circunscribe al "derecho de edificar" al igual que el Código Civil de Bolivia de 1976.Como se ha visto, el nuevo Código Civil del Brasil, a regir a partir del 11 de enero de 2003, también prevé la posibilidad de que el propietario conceda a otro el "derecho de plantar en su terreno por tiempo determnado" (art. 1368).

Por lo demás, como acaba de verse, el artículo $2^{\circ}$. de la ley 25.509, en el camino que estamos analizando para llegar al derecho real de superficie forestal, de cárácter autónomo y temporario sobre cosa propia, "otorga el uso, goce y disposición jurídica de la superficie de un inmueble ajeno con la facultad de realizar forestación o silvicultura y hacer propio lo plantado."

La otra posibilidad que brinda el artículo 2\%. de la ley 25.509 que estamos considerando consiste en la posibilidad de "adquirir la propiedad de plantaciones ya existentes". 
Se trata naturalmente de un supuesto distinto al que acabamos de analizar, en que no existe una plantación existente, pues aquí el de recho de superficie nace a través del acto de adquirir la propiedad de plantaciones ya existentes, separadas naturalmente de la propiedad sobre la cual están implantadas las mismas.

Pensamos asimismo que pueden existir otros modos de constitución de la propiedad superficiaria sobre plantaciones ya existentes, a través por ejemplo de la partición judicial, para el supuesto de que presentadas las operaciones de partición al juez, éste las aprobare a los fines de que el Registro inscriba el derecho real de superficie nacido del acuerdo de todos los herederos (art. 1184, inc. $2^{\circ}$. del Código Civil), como así a través de la adquisición por prescripción breve en el caso en que la superficie hubiera sido constituida por un justo título y el superficiario ejerciere posesión durante diez años. Será posible asimismo adquirir el derecho de superficie en una subasta judicial, en cuyo caso quien así adquiere sabe que solamente incorpora una propiedad superficiaria sobre las plantaciones correspondientes (v. Aída Kemelmajer de Carlucci y Alicia Puerta de Chacón, Derecho real de superficie, Astrea, Bs. As., 1989, ps. 52/55 y nuestro trabajo "La aubasta judicial y los derechos conexos a la cosa subastada, en La Revista del Foro de Cuyo, No. 3, Mendoza, 1991, p. 7 yss.).

El mencionado artículo $2{ }^{\circ}$. concluye prescribiendo que "puede gravarse con derecho real de garantía".

Incuestionablemente la norma torna posible la constitución de hipoteca sobre la propiedad separada. Ello también fue permitido por el Proyecto de 1998 (art. 2026-art. 1990 de la Comisión) (cf. nuestro referido trabajo aparecido en J.A. 2000-II-890), como aś́ en el Proyecto de la llamada Comisión Federal de la Cámara de Diputados de la Nación de 1993 (cf. nuestro trabajo: "El derecho real de superficie en el Proyecto de Código Unificado Civil y Comercial de la Comisión Federal de la Cámara de Diputados de la Nación", (art. 3155), J.A. 1993-IV-921).

Compartimos la inquietud de los distinguidos juristas rosarinos Dres. Nëlson G.A. Cossari y Miguel Angel Luverá, vertida en su trabajo "Derecho real de superficie forestal (Breve comentario a la ley 25.509) (a aparecer en La Ley Litoral) en cuanto sostienen que en esta ley no está suficientemente claro si la hipoteca está habilitada sobre el derecho a forestar. Es lamentable que existe tal duda. Debió consignarse de modo tal posibilidad pues ello hubiera facilitado la posibilidad de hipotecar tal derecho de forestar o de plantar, pues de este modo se habría hecho posible la obtención de fondos para ser aplicados justamente a la forestación, tal cual ocurre con el Proyecto de 1998 (art. 2026; artículo 1990 de la Comisión). De acuerdo a la ley 25.509 solamente seria posible hipotecar las plantaciones ya existentes.

Recordamos de paso que el Proyecto de 1987 prohibió que el derecho de edificiar pudiera ser objeto de gravámenes reales (art. 2614), acorde con la tónica general de dicho Proyecto en el sentido de que no sería posible constituir derechos sobre otros derechos reales (cf. nuestro trabajo: "El derecho real de superficie en el Proyecto argentino de unificación legislativa civil y comercial de 1987" (Centenario del Código Civil Español, 
Universidad Popular Enrique Tierno Galván. Pinoso Alicante, tomo III, Madrid 1889. 1989, Facultad de Ciencias Políticas y Sociología (Universidad Complutense de Madrid), Universidad de Alicante, 1990 , p. 57 y ss.).

En conclusión, el presente artículo $2^{\circ}$. de la ley 25.509 considera al derecho de superficie forestal como a un verdadero derecho real autónomo-de allí la apuntada inclusión en el catálogo de derechos reales contemplado por el art. 2503, C. C. (inciso 8) dispuesto por dicha ley (art. 13). Además, es un derecho real sobre cosa propia de carácter temporario. Se pone así fin a una controversia en torno a la naturaleza del novel instituto incorporado por la ley que estamos analizando.

Cabe recordar en el presente comentario, que el Código Civil de Quebec de 1992, prevé un derecho de superficie que puede ser perpetuo o temporario (art. 1113) y además, puede tener por objeto no solamente construcciones u obras sobre terreno ajeno, sino también plantaciones (art. 1115, primer párrafo).

Por lo demás, el mencionado art. 2․ de la presente ley 25.509 , como se ha visto, contempla las dos posibilidades en los casos en que ello fuere posible, esto es, el derecho de forestar o de plantar (cuando no recayere sobre una plantación ya existente) y el derecho real de superficie forestal.

2. Por su parte el artículo 3․ de la 25.509 dispone que "El propietario del inmueble afectado a superficie forestal conserva el derecho de enajenar el mismo, debiendo el adquirente respetar el derecho real de superficie forestal constituido".

Lo consignado en este artículo no hace más que reiterar lo prescripto por los artículos 2513, 2515 y concordantes del Código Civil en cuanto a la facultad que tiene todo propietario de enajenar la cosa, pues ella constituye una de las atribuciones más amplias de que dispone dicho titular de un dereho real sobre cosa propia (v. nuestro comentario a dichos artículos en nuestro "Código Civil Anotado-Libro III-Derechos Reales", t. 2, citado, páginas 59 y ss. y páginas 69 y ss.). Naturalmente que tal enajenación podrá ser por actos entre vivos o mortis causa.

También parece obvio el deber que tiene el adquirente de respetar el derecho real de superficie forestal constituido oportunamente por el propietario del suelo por aplicación de reglas generales en la materia. De lo contrario sería muy fácil hacer cesar el derecho del superficiario forestal con el simple arbitrio de enajenar la propiedad del inmueble sobre el cual se asentare tal variante del derecho de superficie. De cualquier modo cabe recordar el principio general de libertad del derecho de propiedad, a tenor del artículo 2523, C. Civil, conforme al cual "Cualquiera que reclame un derecho sobre la cosa de otro, debe probar su pretensión, y hasta que no se dé esa prueba, el propietario tiene la presunción de que su derecho es esclusivo e ilimitado". De este modo, en el caso que nos ocupa, si el nuevo adquirente del inmueble desconociere el derecho de sueprficie forestal asentado sobre el mismo deberá probar su pretensión.

Complementando el sentido y alcance del artículo anterior, el artículo $4^{\circ}$. de la ley 25.509 dispone que "El propietario del inmueble afectado a derecho real de superficie forestal no podrá constituir sobre él ningún otro derecho real de disfrute o garantía durante la vigencia 
del contrato,ni perturbar los derechos del superficiario; si lo hace el superficiario puede exigir el cese de la turbación".

En nuestro recordado comentario al Proyecto de Código Civil de 1998 (J.A. 2000. II-890) hemos señalado que el artículo 2020 del mismo (art. 1984 de la Comisión) dispone que "El propietario conserva la disposición juridica y material que corresponde a su derecho, pero no debe turbar los derechos del superficiario. Si lo hace, el superficiario puede exigir el cese de la turbación". O dicho en otras palabras, el propietario conserva las facultades que normalmente le asigna el Código Civil (arts. 2513 a 2522 y concordantes), a condición claro está, de que "no perturbe los derechos del superficiario". Si se diere esta circunstancia, "el superficiario puede exigir el cese de la turbación".

El presente artículo $4^{\circ}$. de la ley que estamos comentando es más enérgico en este sentido, toda vez que establece de modo expreso que el propietario "no podrá constituir sobre el mismo ningún otro derecho real de disfrute o garan tía durante la vigencia del contrato, ni perturbar los derechos del superficiairo". Si así lo hiciere, "El superficiario puede exigir el cese de la turbación".

Cossari y Luverá en el mencionado trabajo señalan con acierto que el derecho que la ley le otorga al titular del inmueble afectado a superficie forestal, se asemeja al derecho que tiene el nudo propietario frente al usufructuario, pues dentro de la normativa del Código Civil, el propietario del inmueble se encuentra facultado a la realiración de todos los actos que le son propios a su carácter de titular del mismo, pero con la sola condición de respetar el derecho del usufructuario durante la vida-si el usufructo se constituyó sin término-o bien durante el término establecido.

El artículo 2914 del Código Civil es muy claro al respecto, al dispone que "El nudo propietario nada puede hacer que dañe el goce del usufructuario o restrinja su derecho". En efecto, aun cuando el nudo propietario conserva el abusus, no por ello podrá realizar cualquier acto material o jurídico que pueda embarazar los derechos del usufructuario. Ya el Digesto establecía que "proprietatis dominus non debebit impidere fructuariam" (1.15.6, tít. 1, lib. 7) (Cf. nuestro comentario a dicho artículo del Código Civil en nuestro "Código Civil Anotado-Libro III-Derechos Reales", t. 3, p. 452, Zavalía, Bs. Aires, 1979, p. 453, en colaboración con Roque Garrido).

También coincidimos con los mencionados autores en cuanto postulan que frente al mencionado art. $4^{\circ}$. de la ley 25.509, resulta concebible la prohibición de la anticresis dado que no se ve cómo el acreedor podría obtener los frutos del predio; en cambio consideran inadecuado impedir que pueda hipotecarse la propiedad, dado que ello no perjudicaría los derechos del superficiario. Pensamos asimismo que si bien la ley no hace referencia a la constitución de derechos personales, ellos se encuentran permitidos, a condición de que no se afecten los derechos del superficiario. En caso de perturbación, naturalmente, el superficiario podrá pedir el cese inmediato de la turbación.

Finalmente, consideramos que este criterio riguroso establecido por el legislador en el presente artículo $4^{\circ}$. de la ley en cuanto a la prohibición de constituir sobre el inmueble ningún otro derecho real de disfrute o garantía durante la vigencia del contrato, 
obedece al propósito de posibilitar al superficiario el pleno goce de su derecho de superficie forestal, sin turbaciones de ninguna indole.

\section{Nacimiento del derecho real de superficie forestal.Publicidad registral.}

Respecto de este punto, el artículo 5‥ de la ley 25.509 dispone: "El derecho real de superficie forestal se adquiere por contrato, oneroso o gratuito, instrumentado por escritura pública y tradición de posesión.

Deberá ser inscripto, a los efectos de su oponibilidad a terceros interesados en el Registro de la Propiedad Inmueble de la jurisdicción correspndiente, el que abrirá un nuevo folio correlacionado con la inscripción dominial antecedente".

Comentaremos inicialmente el primer párrafo, para ocuparnos luego del segundo.

Como fácil resulta de ver la ley ha previsto de modo expreso que el derecho real de superficie forestal se adquiere por contrato, esto es, por acuerdo de las partes interesadas.

Además, tal contrato podrá ser oneroso o gratuito.

Dicho primer párrafo nos indica que se ha hecho aplicación también en el presente caso de la denominada teoría del título y del modo, es decir, del llamado sistema de las dos causas, adoptado por nuestro insigne codificador Vélez Sársfield en materia de transmisión del dominio y de otros derechos reales que se ejercen por la posesión. De este modo, el título será así el acto jurídico causal, otorgado por una persona capaz y legitimada al efecto. En la especie, el contrato de constitución del derecho real de superficie forestal. Y el modo estará constituido por la "tradición de posesión", mencionada de modo expreso en la parte final del primer párrafo del presente artículo 5, transcripto precedentemente.

Establece asimismo dicho párrafo primero de este artículo que tal contrato, deberá ser "instrumentado por escritura pública", en razón de tratarse de un derecho real que recae sobre inmuebles, por lo que resulta de aplicación el art. 1184, inciso $1^{\circ}$. del Código Civil.

El segundo párrafo del art. 5․ expresa, como se ha visto, que "Deberá ser inscripto,a los efectos de su oponibilidad a terceros interesados en el Registro de la Propiedad Inmueble de la jurisdicción correspondiente, el que abrirá un nuevo folio correlacionado con la inscripción dominial antecedente". También en el derecho italiano, el derecho de superficie exige la forma escrita y está sujeto a inscripción registral. Además, tal derecho puede ser adquirido por usucapión (cf. C. Massimo Bianca, Diritto Civile. t. 6. La proprietá, Giuffré Editore, Milano, 1999, p. 556).

La especial circunstancia de encontrarnos frente a un derecho real inmobiliario torna imperativa su inscripción en el Registro de la Propiedad Inmueble de la jurisdicción correspondiente, "a los efectos de su oponibilidad a terceros interesados.." En efecto, nos encontramos en presencia de una inscripción registral inmobiliaria declarativa, por lo que entre las partes el derecho real emergente del contrato respectivo nacerá a partir de su celebración.

El derecho real ha nacido extrarregistralmente y solamente será menester su inscripción registral-como se ha dicho-a los fines de su oponibilidad a terceros interesados. 
Rige el caso, el artículo 2‥ de la Ley Nacional Registral Inmobiliaria No. 17801, que dispone:" "De acuerdo con lo dispuesto por los arts. 2505, 3135 y concordantes del Código Civil, para su publicidad, oponibilidad a terceros y demás previsiones de esta ley, en los mencionados registros se inscribirán o anotarán, según corresponda, los siguientes documentos: $a$ ) Los que constituyan, transmitan, declaren, modifiquen o extingan derechos reales sobre inmuebles.b) Los que dispongan embargos, inhibiciones y demás providencias cautelares. c) Los establecidos por otras leyes nacionales o provinciales".

Como acaba de verse, el mencionado artículo 5․ de la ley 25.509, dispone de modo expreso la inscripción del derecho real de superficie forestal en el Registro de la Propiedad Inmueble de la jurisdicción que corresponda, por lo que tal previsión se halla encuadrada en este inciso c) del referido art. 2\%. de dicha Ley 17801 . Remitimos al comentario a este artículo en nuestro libro "Ley Nacional Registral Inmobiliaria 17801. Comentada. Anotada", 2 da. edición corregida, actualizada y ampliada, Hammurabi. José Luis Depalma.Editor, Buenso Aires, 1999, p.45 y ss., en colaboración con Marta N. Marcolin de Andomo).

Resulta asimismo de aplicación al caso el artículo 3 de dicha ley 17801 que reza:"Para que los documentos mencionados en el artículo anterior puedan ser inscriptos o anotados, deberán reunir los siguientes requisitos: a) Estar constituidos por escritura notarial o resolución judicial o administrativa según legalmente corresponda; $b$ ) Tener las formalidades establecidas por las leyes y estar autorizados sus originales o copias por quien esté facultado para hacerlo; c) Revestir el carácter de auténticos y hacer fe por sí mismo o con otros complementarios en cuanto al contenido que sea objeto de la registración, sirviendo inmediatamente de título al dominio, derecho real o asiento practicable. Para los casos de excepción que establezcan las leyes, podrán ser inscriptos o anotados los instrumentos privados, siempre que la firma de sus otorgantes esté certificada por escribano público, juez de paz of uncionario competente".

Como se desprende de la lectura de este artículo se establecen los diversos requisitos que deben reunir los documentos enumerados en el artículo anterior, entre los cuales, cabe mencionar a la escritura pública que instrumenta la constitución de un derecho real de superficie forestal.

Cabe recordar asimismo en el presente comentario, que por ley 25.345 , se ha agregado el artículo 3 bis, a dicha ley 17801, que reza: "No se inscribirán o anotarán los documentos mencionados en el articulo 2 inc. a), si no constare la clave o código de identificación de las aprtes intervinientes otorgado por la Administración Federal de Ingresos Públcos o por la Administración Nacional de la Seguridad Siocial, de corresponder".

La parte final del articulo 5으 de la ley 25.509 dispone que el Registro de la Propiedad Inmueble de la jurisdicción correspondiente, "abrirá un muevo folio correlacionado con la inscripción dominial precedente".

Se trata de una medida acertada que facilitará la adecuada publicidad del nuevo derecho real de superficie forestal implementado por dicha ley, debiendo crearse así un nuevo folio que se correlacionará con la inscripción dominial precedente. Tal directiva emanada de dicha ley deberá ser implementada por las respectivas reglamentaciones locales. 


\section{Duración del derecho real de superficie forestal.}

El artículo 6 de la ley 25.509 dispone que:"El derecho real de superficie forestal tendrá un plazo máximo de duración por cincuenta años. En caso de convenirse plazos superiores, el excedente no valdrá a los efectos de esta ley".

Este plazo máximo de cincuenta años de duración del derecho real de superficie es ya tradicional en los distintos Proyectos de reformas del Código Civil. En efecto, tanto el Proyecto de 1987, cuanto el de 1993,-ambos referidos solamente al derecho a una construcción ubicada en terreno ajeno-, como el de 1998, que contempla no solamente la propiedad superficiaria sobre construcciones, sino también sobre forestaciones, propugna dicho plazo máximo de cincuenta años. No obstante debe decirse que este útimo admite asimismo como novedad la posibilidad de su renovación, por un lapsoque tampoco exceda de cincuenta años (art. 2018 del Proyecto originario, art. 1982 de la Comisión).

Se ha señalado con acierto que se trata de la suspensión "transitoria del principio de accesión del dominio,que no se deroga. De esta manera se concilian las costumbres enraizadas en nuestra población respeto de la perpetuidad y extensión del dominio del suclo (arts. 2510, 2518 a 2522, Código Civil), con las formas de propiedad coparticipativas que favorecen el mayor aprovechamiento económico de los bienes" (Alicia Puerta de Chacón, Nueva versión del derecho real de superficie, J.A. 2001-11-836).

La ley prevé de modo expreso que si se convinieren plazos mayores a los cincuenta años "el excedente no valdrá a los efectos de esta ley". Ello es natural. Si la ley ha establecido un plazo máximo de cincuenta años, el excedente que pudie re convenirse no valdrá a los efectos de la presente ley. Sólo será válido el contrato por el término máximo de cncuenta años. Se trata de una situación que guarda alguna analogía con lo dispuesto por el artículo 2613 del Código Civil en cuanto prescribe que: "Los donantes o testadores no pueden prohibir a los donatarios o sucesores en sus derechos, que enajenen los bienes muebles o inmuebles que les donaren o dejaren en testamento, por mayor término que el de diez años".

En efecto, si en el supuesto contemplado por dicho disipositivo legal se pactare una prohibición de enajenar los bienes que dejaren los donantes o testadores por un plazo mayor a diez años, conforme a doctrina autoral y jurisprudencial ,prácticamente unánime, tal prohibición sólo valdrá por dicho plazo máximo de diez años (cf. nuestro "Código Civil Anotado-Libro III-Derechos Reales", t. 2, Editorial Zavalia, Bs. As, 1974, ps. 291/92, en colaboración con Roque Garrido).

Finalmente pensamos que una vez vencido el referido plazo de cincuenta años previsto por este artículo $6^{\circ}$. de la ley, sería posible su renovación por un periodo máximo de igual duración, de modo similar a lo que acontece con el artículo 2018 del Proyecto de 1998 (art. 1982 de la Comisión).

\section{Destrucción total o parcial de lo plantado. Derecho de reforestación.}

El artículo 7ㅇ de la ley 25.509 dispone que "El derecho real de superficie forestal no se extingue por la destrucción total o parcial de lo plantado, cualquiera fuera su causa, siempre que el superficiario realice nuevas plantaciones dentro del plazo de tres años". 
Este artículo regula lo que podría denominarse como "derecho de reforestación".

Su fuente inmediata debe buscarse en el art. 2028 del Proyecto de Código Civil . de 1998 (art. 1992 de la Comisión) que dice: "La propiedad superficiaria no se extingue, salvo pacto en contrario, por la destrucción de lo construido o forestado, si el superficiario construye o foresta nuevamente en el plazo de (10) años, o en el menor que se determine".

De este modo, el referido artículo $7^{\circ}$ de la ley 25.509 admite un derecho a plantar de nuevo para el supuesto de destrucción total o parcial de lo plantado, cualquiera fuera su causa, seimpre que el superficiario realice nuevas plantaciones dentro del plazo de tres años.

El menor plazo de tres años establecido por la ley 25.509, en relación al referido plazo de diez años previsto por el Proyecto de 1998, o en el menor que se determine, nos parece razonable, habida cuenta que por ejemplo la reconstrucción de lo edificado previsto por dicho Proyecto -en una de sus variantes-siempre presumiblemente demandará más tiempo que una nueva plantación.

Es natural lo previsto en dicho articulo $7^{\circ}$ de la ley, pues la propiedad superficiaria queda subsistente sobre el terreno correspondiente, como en una especie de letargo, en espera de la correspondiente reforestación. Naturalmente, si en el mencionado plazo de tres años,-a contar a partir de la destrucción de lo plantado- el superficiario no realizare nuevas plantaciones, su derecho se extinguirá.

\section{Extinción del derecho real de superficie forestal}

El artículo 8\%. de la ley 25.509 dispone que: "El derecho real de superficie forestal se extingue por renuncia expresa, vencimiento del plazo contractual, cumplimiento de una condición resolutoria pactada, por consolidación en una misma persona de las calidades de propietario y ssuperficiario o por el no uso durante tres años".

Como se desprende de la lectura del texto transcripto,se prevé en primer lugar la extinción del deecho real de superficie forestal por renuncia expresa. Tratándose de un derecho patrimonial, el titular del mismo puede perfectamente renunciarlo.

La ley impone una condición: que la renuncia sea expresa. Ello así a los fines de que no quede ninguna duda acerca de la abdicación de su derecho por parte del superficiario forestal. Tal exigencia se halla en consonancia con la letra y el espíritu del artículo 874 del Código Civil en cuanto consigna que "La intención de renunciar no se presume, y la interpretación de los actos que induzcan a probarla debe ser restrictiva".

La segunda causal de extinción del derecho se superficie forestal se produce por el vencimiento del plazo contractual.

Ya hemos visto anteriormente, que conforme al artículo 6. de la ley 25.509, el derecho real de superficie forestal tendtá un plazo máximo de cincuenta años. Es posible por tanto pactar un plazo menor. De este modo cuando se produjere el vencimiento del plazo contractual, naturalmente se extinguirá el derecho de superficie forestal.

Comentando el punto sostiene Ramón Roca Sastre al ocuparse de la extinción del derecho de superficie por el transcurso del tiempo de duración fijado, o sea, por finalizar el 


\section{El derecho real de superficie forestal en el ordenamiento juridico positivo Argentino 175}

plazo, que se trata del supuesto clásico de extinción de un derecho por caducidad, debido a haberse agotado el tiempo preestablecido para su duración al constituirse. Ya recuerda que la ley del Suelo de España, establece que "el derecho de superficie se extinguirá por el transcurso del plazo que se hubiere determinado al constituirlo" (Ramón Roca Sastre, Derecho hipotecario, t. III, páginas 583/584, Editorial Bosch, Barcelona, 1968).

La otra causal contemplada por el artículo que estamos comentando refiere al "cumplimiento de una condición resolutoria pactada". Ello se halla en consonancia con los principios generales establecidos en nuestro Código Civil en materia de obligaciones bajo condición resolutoria. Así, el art. 553 de dicho cuerpo legal prescribe que "La obligación es formada bajo condición resolutoria, cuando las partes subordinaren a un hecho incierto y futuro la resolución de un derecho adquirido".

Otra causal mencionada por dicho art. $8^{\circ}$ de la ley 25.509 refiere a la "consolidación en una misma persona de las calidades de propietario y superficiario".

Tal consolidación se opera por la reunión en una misma persona de las calidades de propietario del suelo y de superficiario. Ello así, por cuanto el derecho real de superficie forestal supone la existencia de calidades distintas en las personas del dueño del suelo y del superficiairo forestal. Obviamente si ambas calidades se confunden, el derecho real de superficie forestal se extinguirá .

Finalmente, dicho art. $8^{\circ}$ de la ley prevé como causal de extinción del derecho real de superficie forestal al "no uso durante tres años".

Se ha señalado acertadamente que el no uso consiste en no forestar dentro del plazo legal, justificándose este modo de extinción como en las demás desmebraciones del dominio, dado que el dueño del suelo acepta una suspensión temporaria de la accesión, con la sola condición de su forestación en las condiciones pactadas. La norma hubiera sido más acertada si la extinción por el no uso se limitase al derecho a forestar-como lo dispone el art. 2026 del Proyecto de 1998 (art. 1990 de la Comisión) y no respecto a la propiedad superficiaria que es sobre cosa propia (cf.Cossari y Luverá, trabajo citado).

\section{Obligaciones que pesan sobre el superficiario forestal}

Sobre este particular el art. 9 de la ley 25.509 prescribe que "La renuncia del derecho por el superficiario, o su desuso o abandono, no lo libera de sus obligaciones".

Acá se hace referencia nuevamente a la posibilidad de renuncia del derecho de superficie forestal por lo que remitimos a las consideraciones formuladas en ocasión de analizar el artículo 8 de la ley.

Se menciona asimismo al desuso o abandono del derecho. Acerca del abandono han señalado Kemelmajer de Carlucci y Puerta de Chacón, en relación al art. 2614 del Proyecto de 1987, que sólo preveía el derecho de edificar y el derecho de superficie sobre la edificado-que esta causal configura un acto unilateral de voluntad seguido del desprendimiento de la posesión, que debe ser cuidadosamente distinguido del no uso, que extingue el derecho de edificar: La propiedad superficiaria en cambio, como toda propiedad, subsiste independientemente del ejercicio que se haga de ella (art.2510). Claro está que 
si un tercero realiza actos posesorios sobre el suelo y la propiedad superficiaria durante el plazo y con los recaudos establecidos por la ley, prescribirá y se extinguirá de este modo la propiedad anterior sobre el suelo y sobre el edificio (Kemelmajer de Carlucci, Aída y Puerta de Chacón, Alicia, Derecho real de superficie, Buenos Aires, Astrea, 1989, p. 59).

Esta es la tesis correcta. De allí que hayamos adherido a la crítica formulada al art. 8 de la ley, en cuanto hubiera sido más apropiado que el mismo no se limitase al derecho de forestar y no respecto de la propiedad superficiaria que es sobre cosa propia, y a la que resulta de aplicación dicho artículo 2510 y concordantes del Código en orden a la perpetuidad del dominio.

Añádase que se ha sostenido asimismo -con referencia al Proyecto de Código Civil de 1998-que tanto la renuncia al derecho de construir o forestar cuanto el abandono de la propiedad superficiaria deberán ser expresos, manifestados por escritura pública (por tratarse de derechos reales sobre inmueble) e inscriptos en el Registro para su oponibilidad a terceros interesados de buena fe (art. 2156 del Proyecto (art. 2148 de la Comisión) (Irene Pujol de Zizzias y Martha Linares de Urrutigoity, Consideraciones en tomo al derecho real de superficie (conforme al Proyecto de Código Civil de la República Argentina unificado con el Código de Comercio, entrega de J.A. del 16 de enero de 2002).

Ahora bien, como se ha visto, para el supuesto de renuncia por el superficiario, o su desuso o abandono, el mencionado artículo $9^{\circ}$ de la ley deja expresamente establecido que "no lo liberan (al superficiario) de sus obligaciones".

Ello significa que las obligaciones o gravámenes asumidos por el superficiario forestal continuarán con los alcances propios de los mismos. La extinción del derecho de superficie forestal no se extenderá al suelo.Por lo demás, como lo hemos señalado oportunamente en relación al Proyecto de 1998, los gravámenes constituidos por el superficiario no podrán durar más allá del plazo de vigencia de su derecho de superficie (cf. nuestro referido trabajo "El derecho de superficie en el Proyecto de Código Civil de 1998", J.A. 2000-II-890). De modo que las obligaciones-naturalmente,de indole personalcontraídas por tal superficiario se proyectarán más allá de la extinción del detecho de superficie forestal.

IX. El supuesto especial de la extinción del derecho real de superficie forestal por consolidación

Sobre este punto el artículo 10 de la ley 25.509 prescribe que "Los gravámenes constituidos por el propietario o superficiario continúan con los alcances propios de cada gravamen".

Si bien existe una diferencia con el texto del art. 2022 del Proyecto de 1998 en cuanto éste dispone que "Los gravámenes constituido por el propietario o superficieario continuan con los alcances propios de cada gravamen" pensamos que en esencia se da una coincidencia esencial entre ambos textos.

En efecto, en nuestro comentario a dicho art. 2022 de dicho Proyecto de 1998 hemos dicho oportunamente que se trata de una fórmula similar al art. 3158 del Proyecto 
de Reformas de 1993. Es lógico que la consolidación-o confusión, como la llaman algunos autores-traiga como consecuencia la extinción del derecho de superficie, toda vez que este derecho real supone necesariamente la existencia de dos titulares de derechos reales ligados entre sí, esto es, el propietario del suelo y el superficiairo, como también lo puntualizamos precedentemente. Si tales titularidades se unen en una misma persona, naturalmente dejará de existir el derecho de superficie.

Por tanto, si el derecho del superficiario se extinguiere por consolidación-ya sea a través de la via de la sucesión mortis causa o bien por actos entre vivos, mutuo distracto, etc., los gravámenes reales (vgr. hipoteca) o personales constituidos tanto por el propietario cuanto por el superficiario, subsistirán, con sus mismos alcances, como si el referdios derecho de superficie no se hubiera extinguido. Desde luego que tales gravámenes no podrán subsistir más allá del plazo requerido en la superficie. Se trata de un criterio distinto al sustentado por el art. 2670, C.Civil, pues la referida consolidación en la letra y en el espíritu de dicho art. 2022 del Proyecto de 1998, no podrá afectar los derechos a favor de los cuales se hubieren constituido los gravámenes reales o personales (cf. Kemelmajer de Carlucci y Puerta de Chacón, op. cit., ps. $91 / 92$ y nuestro referido "Código Civil AnotadoLibro III-Derechos Reales", t. 2, p. 424, en colaboración con Roque Garrido y nuestro mencionado trabajo publicado en J.A. 2000-II-900).

En este mismo orden de ideas señala Atilio Américo Connejo, refiriéndose al art. 2617 del Proyecto de 1987, párrafo similar al mencionado art. 2022 del Proyecto de 1998 que "Esta es una modificación sustancial al art. 2670 ya que la extinción por consolidación que se opera por voluntad del dueño y del superficiario no puede perjudicar los derechos de los terceros acreedores titulares de deechos reales. Si por ejemplo existiera una hipoteca sobre la propiedad superficiaria, no obstante que al extinguirse el derecho de superficie no cabe hablar de propiedad superficiaria, aun cuando mientras dure la hipoteca va a subsistir al solo fin de ser objeto del derecho real que no se extingue a pesar de la consolidación" (Atilio Américo Cornejo, El deecho real se superficie en el Proyecto de Unificacion Civily Comercial", La Ley, t. 1987-D-1121, cit. por Cossari y Luverá en el mencionado trabajo"). Una situación similar encontramos en el derecho italiano frente al Código Civil de 1942 al producirse la extinción de la superficie por consolidación o confusión (cr. Mario Zaccagnini y Antonio Palatello, Enfiteusi Superficie Oneri Reali, Jovene Editore, Napoli, 1984, p. 343).

Lo expuesto resulta aplicable al texto del artículo 10 de la ley 25.509 , toda vez que en el supuesto de extinción del derecho real de superficie forestal por consolidación, los derechos y obligaciones del propie tario y del superficiario continuarán con sus mismos alcances y efectos.

Es decir, que consecuentemente los derechos reales o personales que pudieren haber constituido tanto el propietario del suelo, cuanto el superficiario forestal continuarán con sus mismos alcances y efectos. Esto es, como si por una suerte de ficción la consolidación no se hubiera producido.Desde luego que en ningún caso tal separación ficticia durará más allá del plazo por el cual se hubiera pactado el derecho de superficie. 


\section{$X$. Efectos de la extinción del derecho real de superficie forestal.}

El artículo 11 de la ley 25.509 dispone que "Producida la extinción del derecho realde superficie forestal, el propietario del inmueble afectado, extiende su dominio a las plantaciones que subsistan, debiendo indemnizar al superficiario, salvo pacto en contrario, en la medida de su enriquecimiento".

La regla general en esta materia es la de que luego de operarse la extinción del derecho de superficie recobra su vigencia el principio de accesión disciplinado básicamente por el art. 2519 del Código Civil, por lo que renace en cabeza del dueño del suelo la plenitud del dominio. De este modo, lo plantado en el inmueble por el superficiario pasará a ser propiedad de dicho propietario del terreno.

Dicho articulo 11, que acaba de transcribirse coincide en su esencia con el art. 2023 del Proyecto de 1998 que dice: "En todos los casos, producida la extinción del derecho de superficie, el titular del emplazamiento extiende su derecho sobre las construcciones o forestaciones efectuadas que subsistan, debiendo indenmizar al superficiario, salvo pacto en contrario, en la medida del enriquecimiento".

Ahora bien, en el presente comentario, cabe recordar que durante la vigencia del derecho de superficie forestal y como contrapartida de la propiedad superficiaria de las correspondientes plantaciones a que tiene derecho el titular de la misma, el dominus soli, entre otras atribuciones, tiene la de percibir una contraprestación o canon (solarium, en el antiguo derecho romano) para el supuesto de una constitución onerosa de tal derecho real. Se recuerda, que de acuerdo al artículo $5^{\circ}$ de la ley 25.509, el derecho real de superficie forestal, puede adquirise tanto por contrato oneroso, cuanto por uno de carácter gratuito.

Cabe recordar que Roca Sastre, en el Derecho español, que en la constitución onerosa del derecho de superficie, la contraprestación podrá consistir en la entrega de un precio o en el pago de un cano periódico cuando este último será lo corriente. Aclaba que a ambas prestaciones se refiere el art. 16, B), del Reglamento Hipotecario Español.Además, la contraprestación podrá ser algo que no consista en ningún precio ni canon dinerario, por derivar del derecho de superficie de un contrato de permuta, la contraprestación podrá ser la atribución de alguno o de algunos de los pisos o elementos a integrar la propiedad separada superficiaria (Roca Sastre, "Derecho hipotecaario", Ed. Bosch, Barcelona, 1968, t. III, p. 580).

Pensamos que tales reglas, con las adaptaciones del caso, pueden resultar de aplicar al derecho real de superficie forestal regulado por la ley 25.509 .

Uno de los problemas que se plantean en esta materia es el relacionado con el momento a partir del cual se producen los efectos de la extinción del derecho de superficie. Conforme al criterio consignado en nuestro referido trabajo aparecido en J.A. 2000-II-901, pensamos que se produce la adquisición ipso iure de las plantaciones por parte del dueño del terreno, sin necesidad de tradición previa (v. referida obra de Kemelmajer de Carlucci y Puerta de Chacón, ps. 63/64). 
De esta manera, en todos los casos de extinción del derecho de superficie forestal , el dueño del terreno recupera automáticamente la plenitud de su dominio. La regla de la accesión del referido art. 2519 del Código Civil cobra así su plena operatividad.

El mencionado art. 11 de la ley, transcripto precedentemente, dispone en su parte final que el dueño del inmueble debe "indemnizar al superficiario, salvo pacto en contrario, en la medida de su enriquecimiento".

Por tanto, la regla general es la de que el dueño del suelo debe indemnizar al superficiairo en la medida del enriquecimiento. En caso de discordancia en torno al valor de las plantaciones efectuadas, se apelará corrientemente a tasaciones, tanto en el ámbito extrajudicial, cuanto en el juicio que pudiere promoverse.

Pero, conforme a dicho art. 11, in fine, se admite la posibilidad de escapar a dicha regla de indemnización, a través de un pacto en contrario. Tal regla reconoce su antecedente en el articulo 1538 del Código Civil de Portugal de 1966.

Pensamos asimismo que el superficiario podrá ejercer el derecho de retención sobre lo plantado hasta tanto el dominus soli abone la indemnización correspondiente.

En el presente comentario resulta asimismo de interés recordar, como lo hemos hecho oportunamente al comentar la norma similar del Proyecto de 1998, (J.A. 2000-II901), que se ha sostenido en el Derecho italiano, que cuando en el negocio de constitución del derecho real de superficie "por tiempo determinado", se hubiere establecido la obligación del dueño del terreno de pagar al propietario de la construcción en el momento en que la misma pasará al patrimonio de aquél-por el vencimiento del término-el derecho a cobrar tal compensación deberá ser reconocida a favor de la persona a cuo favor fue estipulada la misma. De esta manera, esta persona tendrá derecho a tal indemnización, aun cuando una persona distinta fuere titular del derecho de superficie al vencimiento del término, por haberse operado una transferencia del derecho a su favor (Lino Salis, El derecho de superficie, Turín, 1958, p. 112). Aun cuando el mencionado artículo 11 de la ley 25.509, transcripto precedentemente consigne que la indemnización correspondiente-por la plantación que pasará al dueño del suelo- debe ser abonada "al superficiario", pesnamos que la posibilidad mencionada, admitida por la doctrina italiana, también puede resultar de aplicación a nuestro derecho, a condición-claro está-de que se hubierea pactado oportunamente tal alternativa.

\section{Modificación del artículo 2614 del Código Civil.}

El artículo 12 de la ley 25.509 reza: "Modifícase el artículo 2614 del Código Civil, el que quedará redactado de la siguiente manera: Artículo 2614: Los propietarios de bienes raíces no pueden constituir sobre ellos derechos enfitéuticos, ni imponerles censos ni rentas que se extiendan a mayñor término que el de cinco años, cualquiera sea el fin de la imposición; ni hacer en ellos vinculación alguna".

Al respecto cabe recordar que nuestro codificador Vélez Sarsfield, fiel a la regla del "numerus clausus" o de la tipicidad de los derechos reales, dispuso en el art. 2502 del Código Civil: "Los derechos reales sólo pueden ser creados por la ley. Todo contrato o disposición 
de última voluntad que constituyese otros derechos reales, o modificase los que por este Código se reconocen, valdrá sólo como constitución de derechos personales, si como tal pudiese valer".

Con ello hubiera sido suficiente para que no se constituyesen otros derechos teales que los creados por la ley. Pero como entraba a regir un nuevo Código Civil, que reemplazaba a la legislación que hasta hace momento había regido en nuestra Patria, que admitía algunos derechos reales que Vélez no consideraba adecuados mantener vigentes o posibilitar su futura creación, atento la realidad de nuestra Patria,y a fin de que no quedara ninguna duda al respecto, decidió enfáticamente que los derechos reales enumerados en el artículo 2614 del Código Civil, en la redacción velezana que decía: "Los propietarios de bienes raíces no pueden constituir sobre ellos derechos enfitéuticos, ni de superficie, ni imponersles censos, ni rentas que se extiendan a mayor término que el de cinco años, cualquiera que sea el fin de la imposición; ni hacer en ellos vinculación alguna", no podian ser constituidos en el futuro.

Frente a la nueva circunstancia emergente de la ley 25.509 que admite el derecho de superficie en una de sus variantes, esto es, el derecho real de superficie forestal, en la redacción actual de dicho artículo 2614, dispuesta por dicha ley, en su artículo 12, se suprima naturalmente la mención al derecho de superficie, que tenía el texto originario de este articulo.

A través de este comentario hemos procurado poner de relieve los aspectos más salientes acerca del derecho real de superficie forestal introducido a nuestro derecho positivo a través de la mencionada ley 25.509."complementaria del Código Civil"-0.0 (art. 14 de la misma) - haciendo votos por que su implementación y aplicación redunde en beneficio de los habitantes de nuestra querida Patria, tal cual lo venimos postulando desde hace casi dos décadas. 